\title{
Noninvasive Ventilatory Support for Acute Hypercapnic Respiratory Failure
}

\author{
Nicholas S Hill, Giulia Spoletini, Gregory Schumaker, and Erik Garpestad
}

\author{
Introduction \\ Rationale for NIV \\ Epidemiology \\ Mechanisms of Action of Noninvasive Approaches to Treat Acute Hypercapnic \\ Respiratory Failure \\ Indications for NIV in Acute Hypercapnic Respiratory Failure \\ COPD Exacerbations \\ Asthma Exacerbations \\ Cystic Fibrosis \\ Decompensated Obesity Hypoventilation Syndrome \\ HFNC in Acute Hypercapnic Respiratory Failure \\ Rationale for HFNC to Treat Acute Hypercapnic Respiratory Failure \\ Physiologic Studies That Used HFNC in Subjects With COPD \\ Comparison Between HFNC and NIV \\ Evidence for Efficacy of HFNC in Acute Hypercapnic Respiratory Failure \\ Conclusions
}

\begin{abstract}
Noninvasive ventilation is well established as the ventilatory modality of first choice to treat acute or acuteon-chronic hypercapnic respiratory failure in patients with COPD by improving dyspnea and gas exchange, avoiding the need for intubation, and reducing morbidity and mortality rates. Noninvasive ventilation also offers benefit for patients with COPD and with accompanying pneumonia or with hypercapnic respiratory failure in postextubation, postoperative, and do not intubate settings. Noninvasive ventilation, in addition, offers benefit in other forms of acute hypercapnic respiratory failure, including those caused by asthma, cystic fibrosis, and obesity hypoventilation. A newer form of noninvasive ventilatory assistance, high-flow nasal cannula, has emerged in recent years as a technique to not only oxygenate effectively but also to improve ventilatory efficiency and reduce the work of breathing in patients with severe COPD. Results of recent studies indicate that high-flow nasal cannula therapy can benefit some patients with acute hypercapnic respiratory failure, either instead of or in combination with noninvasive ventilation, but more study is needed. Key words: acute hypercapnic respiratory failure; COPD; high-flow nasal cannula; NIV; noninvasive ventilation; ventilatory modality [Respir Care 2019;64(6):647-657. ( 2019 Daedalus Enterprises]
\end{abstract}

\section{Introduction}

Noninvasive ventilation (NIV) has seen increasing use in the acute care setting over the past 2 decades, most dramatically for hypercapnic respiratory failure. ${ }^{1}$ In particular, patients with acute hypercapnic respiratory failure due to COPD respond well to NIV, which is now considered the ventilatory modality of first choice for these entities, ${ }^{2,3}$ although there is evidence that supports the use of

Dr Hill presented a version of this paper at the 57th RESPIRATORY CARE Journal Conference, Noninvasive Respiratory Support in Adults, held June 14-15, 2018, in St Petersburg, Florida. 
NIV to treat acute hypercapnic respiratory failure of other etiologies as well. ${ }^{2}$ NIV generally refers to positive-pressure ventilation administered via a noninvasive interface, usually a full face mask, although reports of successful treatment of acute hypercapnic respiratory failure when using $\mathrm{CPAP}^{4,5}$ and negative-pressure ventilation ${ }^{6}$ have appeared in the older literature. More recently, there has been emerging interest in using high-flow nasal cannula (HFNC) to treat acute hypercapnic respiratory failure. ${ }^{7}$ The following article reviews the rationale for using NIV in preference to invasive mechanical ventilation, the epidemiology of use over the past 2 decades, mechanisms of action, and evidence for using NIV to treat various forms of hypercapnic respiratory failure. Emerging evidence for applications of HFNC in acute hypercapnic respiratory failure is also reviewed, with potential indications as well as caveats.

\section{Rationale for NIV}

NIV has a number of advantages over invasive ventilation, including improved safety and outcomes. By avoiding invasion of the upper airway, NIV eliminates trauma and discomfort associated with airway insertion and leaves upper-airway protective mechanisms intact, which thus reduces the occurrence of health-care-associated pneumonias. ${ }^{8}$ Use of NIV is also associated with fewer invasive procedures and hospital-acquired infections overall. ${ }^{9}$ Due to the reduced morbidity and reduced need for sedation, patients treated with NIV may spend less time in the ICU ${ }^{10}$ or hospital, which thus lowers health-care costs. ${ }^{11}$

\section{Epidemiology}

In view of the above-mentioned advantages and the accumulating evidence, the use of NIV to treat acute hypercapnic respiratory failure in COPD exacerbations has been increasing worldwide over the past 20 years. An early observational study of NIV utilization for subjects with acute respiratory failure due to COPD or acute cardiogenic pulmonary edema in a single 26-bed French ICU revealed an increase from $20 \%$ of ventilator starts in 1994 to nearly $90 \%$ in $2001 .{ }^{9}$ In association with this increase, the occur-

Dr Hill discloses relationships with Philips Respironics and Fisher \& Paykel.

The remaining authors have disclosed no conflicts of interest.

Correspondence: Nicholas S Hill MD, Division of Pulmonary, Critical Care and Sleep Medicine, Tufts Medical Center, 800 Washington St \#257 Boston, MA 02111. E-mail: nhill@tuftsmedicalcenter.org.

DOI: $10.4187 /$ respcare.06931 rence of health-care-acquired pneumonias and ICU mortality fell from $20 \%$ to $8 \%$ and from $21 \%$ to $7 \%$, respectively. Subsequent surveys of European ICUs performed in 1997 and 2002 showed that NIV use increased from $16 \%$ to $23 \%$ of overall ventilator starts. ${ }^{12,13}$ Another serial survey of ventilator use in international ICUs performed in 1998 and 2004 showed that NIV use for patients with COPD increased from $48 \%$ to $78 \%$ of ventilator starts. ${ }^{14,15}$

Similar trends were observed in surveys of acute-care hospitals in the northeastern United States. These showed an increase in the overall ventilator start rate for NIV, from $20 \%$ in $2002^{16}$ to nearly $40 \%$ in $2008^{17}$ and for an NIV start rate for patients with COPD from an estimated 33\% in 2002 to $80 \%$ in 2008. More-recent studies that used large data analyses in the United States showed continuations of these trends. Chandra et $\mathrm{al}^{1}$ analyzed $>7.5$ million admissions for COPD exacerbations in the United States Nationwide In-patient Sample between 1998 and 2008. They found an increase in NIV starts from $1 \%$ to $4.5 \%$ ( $462 \%$ increase), whereas use of invasive ventilation dropped from $6 \%$ to $3.5 \%$ (42\% decrease). When using the Premier Database, Stefan et al ${ }^{18}$ found similar trends between 2001 and 2011, with NIV use increasing by $15 \%$ annually and the largest proportionate increase in the $>85$ $\mathrm{y}$ age group.

These trends demonstrate a large increase in the use of NIV worldwide over 2 decades, but this varies not only between countries but also between institutions in a single country. A 2003 national audit in the United Kingdom found that $39 \%$ of ICUs were not applying NIV to patients with COPD, ${ }^{19}$ and a 2008 survey in Korea found that only 2 of 24 university ICUs were using NIV, which constituted only $4 \%$ of total ventilator starts. ${ }^{20}$ These latter findings underline the importance of continuing to provide education to providers worldwide via dissemination and implementation of guideline recommendations.

\section{Mechanisms of Action of Noninvasive Approaches to Treat Acute Hypercapnic Respiratory Failure}

Hypercapnic respiratory failure ultimately arises from a failure to adequately ventilate the gas-exchanging areas of the lungs due to an imbalance of the demand and supply for breathing work. Factors that increase work of breathing include increased $\mathrm{CO}_{2}$ production, increased mechanical breathing load due to stiffening (increased elasticity) of the lungs and/or chest wall, or loss of lung elasticity, which leads to hyperinflation of the lungs as well as increased airway resistance. Factors that reduce the ability to supply ventilatory work include weakness or mechanical disadvantage of respiratory muscles, respiratory muscle fatigue, increased airway resistance, and a depressed respiratory drive. 
Table 1. Indications for Noninvasive Ventilation in Acute Respiratory Failure

\begin{tabular}{l}
\hline \hline \multicolumn{1}{c}{ Indication } \\
\hline Strong \\
Acute or acute-on-chronic hypercapnic respiratory failure due to \\
COPD \\
Acute cardiogenic pulmonary edema \\
Intermediate \\
Acute respiratory failure in patients who are immunocompromised \\
Hypercapnic respiratory failure due to COPD associated with \\
pneumonia and in postoperative and postextubation settings \\
Respiratory failure and/or compromise in patients with COPD and \\
with a do-not-intubate status \\
Weak \\
Acute or acute-on-chronic hypercapnic respiratory failure due to \\
asthma, cystic fibrosis, or obesity hypoventilation \\
\hline
\end{tabular}

Noninvasive approaches use a variety of mechanisms to restore the balance of the supply and demand of breathing work. CPAP alone reduces work of breathing in patients with severe COPD by counterbalancing auto-PEEP, the elevated intra-alveolar pressure due to incomplete emptying, sometimes referred to as dynamic hyperinflation. Extrinsic PEEP (5-10 $\mathrm{cm} \mathrm{H}_{2} \mathrm{O}$ ) applied via a mask reduces the drop in pressure needed to create a negative pressure gradient and initiate air flow for the next breath. Pressure support also reduces the work of breathing by reducing the force inspiratory muscles must apply during inspiration (like power steering). The combination of PEEP and pressure support reduces diaphragmatic work in patients with COPD exacerbations more effectively than either one alone, ${ }^{21,22}$ which helps to mitigate excessive work of breathing that leads to respiratory muscle fatigue and avoids worsening respiratory failure. Physiologic benefits of NIV in patients with COPD include more-rapid improvements in $\mathrm{P}_{\mathrm{aCO}_{2}}$, heart rate, and dyspnea scores than conventional oxygen therapy. ${ }^{23}$

\section{Indications for NIV in Acute Hypercapnic Respiratory Failure}

\section{COPD Exacerbations}

Acute or acute-on-chronic hypercapnic respiratory failure due to a COPD exacerbation is the best-established indication for NIV (Table 1). For at least 15 years, guidelines have considered NIV as the ventilatory modality of first choice to treat COPD exacerbations that require ventilatory assistance. The efficacy of NIV to treat COPD exacerbations has been apparent for over 20 years. ${ }^{21,23}$ Multiple randomized controlled trials (RCT) provide solid supportive evidence of the benefits of NIV in COPD exacerbations, including more-rapid improvements in $\mathrm{P}_{\mathrm{aCO}_{2}}$,
Table 2. Selection of Patients With Acute Hypercapnic Respiratory Failure for Noninvasive Ventilation

\begin{tabular}{l}
\hline \hline \multicolumn{1}{c}{ Selection Criteria } \\
\hline 1. Determine the need for ventilatory assistance \\
Moderate-to-severe dyspnea \\
Tachypnea ( $\geq 24$ breaths/min) \\
Increased accessory muscle use \\
Thoracoabdominal paradox \\
$\mathrm{pH}<7.34 ; \mathrm{P}_{\mathrm{aCO}}>45 \mathrm{~mm} \mathrm{Hg}$ \\
2. Determine the presence of contraindications \\
Medical instability, including hypotensive shock, massive \\
gastrointestinal bleed, acute ST elevation myocardial infarction \\
Agitation, uncooperativeness \\
Inability to protect the airway \\
Inability to accommodate the mask
\end{tabular}

heart rate, and dyspnea scores than conventional therapy. ${ }^{24}$ Meta-analyses by Lightowler et $\mathrm{al}^{25}$ and Quon et $\mathrm{al}^{26} \mathrm{ob}-$ served relative risk reductions with NIV of $0.42 \%$ and $65 \%$ for intubation, respectively; $0.41 \%$ and $55 \%$ for mortality, respectively; and an absolute reduction of 3.21 and 1.9 in hospital days, respectively (all $P<.05$ ), compared with subjects who were conventionally treated. More recently, a propensity-adjusted comparative effectiveness analysis that used data from 420 hospitals and $>25,000 \mathrm{pa}-$ tients showed that the subjects with COPD who were treated with initial NIV compared with those treated with invasive ventilation had a lower risk of mortality (odds ratio 0.54 , 95\% CI $0.48-0.61$ ) and hospital-acquired pneumonia (odds ratio $0.53,95 \%$ CI $0.44-0.64$ ), lower costs (cost ratio $0.68,95 \%$ CI $0.67-0.69$ ), and a shorter length of stay (stay ratio $0.81,95 \%$ CI $0.79-0.82$, all $P<.05$ ). ${ }^{27}$ The recent European Respiratory Society/American Thoracic Society practice guideline on NIV recommended NIV as the first ventilatory option to treat patients with severe COPD exacerbations, but they also recommended against routine use of NIV for patients with mild COPD exacerbations. ${ }^{3}$

Patients with COPD and acute respiratory failure are good candidates for NIV in other settings as well. NIV to facilitate early removal of an endotracheal tube, ${ }^{28,29}$ to avert the need for re-intubation after a standard extubation, ${ }^{30}$ to use in the postoperative setting, ${ }^{31}$ and to use when there is a concomitant pneumonia ${ }^{10}$ are all supported by RCTs. In patients with COPD and with a do not intubate status, use of NIV is supported by observational data. ${ }^{32,33}$

Selection criteria for initiation of NIV in patients with hypercapnic respiratory failure (Table 2 ) is a 2-step process that first determines whether the patient needs ventilatory assistance based on clinical and gas exchange criteria. If so, then the next step is to determine whether the patient is a good candidate for NIV. If there are contraindications, then invasive ventilation would be preferred unless the patient has decided against it. NIV should be 
initiated as soon as the patient meets criteria for needing ventilatory assistance, neither sooner nor later. Premature initiation wastes resources and increases intolerance rates, and delayed initiation permits patients to deteriorate to the point when intubation is unavoidable. Delay of a needed intubation is to be assiduously avoided; this raises the possibility of an emergency intubation or respiratory arrest that greatly increases the risk of morbidity or mortality.

\section{Asthma Exacerbations}

Reports that date back more than 20 years indicate that NIV can improve gas exchange and avoid intubation in patients with severe, recalcitrant asthma, ${ }^{34,35}$ but relatively few RCTs have been done. One small RCT found that NIV compared with sham treatment improved $\mathrm{FEV}_{1}$ more after $3 \mathrm{~h}$ of therapy $\left(\mathrm{FEV}_{1} \%: 53.5\right.$ versus $\left.28.5 ; P<.05\right)$ and that fewer subjects on NIV required hospital admission. ${ }^{36}$ To explore the idea that positive pressure might act as a bronchodilator, a subsequent study withheld bronchodilators for the first hour after initiation of "high" or "low" bi-level ventilation (inspiratory and expiratory pressures of 8 and $6 \mathrm{~cm} \mathrm{H}_{2} \mathrm{O}$ and 6 and $4 \mathrm{~cm} \mathrm{H}_{2} \mathrm{O}$, respectively) or conventional oxygen therapy. ${ }^{37}$ The "high-dose" NIV group had a $20 \%$ improvement in $\mathrm{FEV}_{1}$ over baseline compared with no improvement in controls treated with oxygen $(P<.05)$. A third RCT enrolled subjects with severe airway obstruction and respiratory distress (average $\mathrm{FEV}_{1}$ of $21 \%$ predicted; frequency of 36 breaths/min) to receive NIV or conventional therapy with oxygen supplementation. ${ }^{38}$ NIV use was associated with a trend toward more improvement in $\mathrm{FEV}_{1}$ in the first hour, less salbutamol use, and a shorter hospital length of stay ( 38 versus $54 \mathrm{~h}$ ). ${ }^{38}$ However, the clinical importance of these differences is in doubt because, in both the NIV and control groups, intubation rates were similarly low and there were no mortalities.

Although not definitive, these findings were encouraging and indicated that NIV could, perhaps by virtue of a positive pressure-induced bronchodilator effect, help to improve air flow early on during severe asthma exacerbations. This was consistent with some experimental asthma models that show evidence of improved air flow when positive pressure is applied, ${ }^{39}$ but this has not been adequately studied in a clinical setting. A Cochrane review considered NIV for asthma promising but controversial ${ }^{40}$ and the European Respiratory Society/American Thoracic Society guideline made no recommendation due to a lack of evidence. ${ }^{3}$ Even so, NIV can be considered to treat acute severe asthma and, anecdotally, may be useful to avoid intubation in status asthmaticus, although more studies are clearly needed to test this possibility and to assess the clinical utility of its apparent early bronchodilator effect. In the meantime, caution should be exercised because some patients with severe asthma can deteriorate rapidly and develop very-severe obstruction, which makes ventilation difficult, even via the invasive route.

\section{Cystic Fibrosis}

For at least 25 years, NIV has been used to treat patients with end-stage cystic fibrosis who are acutely deteriorating. The largest series to date enrolled 113 subjects treated with NIV for an exacerbation of cystic fibrosis. ${ }^{41}$ Ninety of these subjects had very severe airway obstruction (median $\mathrm{FEV}_{1} / \mathrm{FVC}, 0.5$ ) and were under consideration or were actually listed for lung transplantation. Twenty eight survived to transplantation, 10 remained on the list at the time of reporting, and the remainder died. NIV improved oxygenation but not hypercapnia, which was severe (range, 60-80 mm Hg). Among 23 subjects not considered for lung transplantation, mortality was $87 \%$ after an average of $45 \mathrm{~d}$. Thus, NIV may serve as a rescue therapy to provide a bridge to transplantation for patients with acutely deteriorating cystic fibrosis, ${ }^{42}$ but control of airway secretions is still a huge challenge, and mortality is high if lung transplantation is not a consideration. A Cochrane review from 2017 concluded that NIV in patients with cystic fibrosis may be a useful adjunct to other techniques for secretion removal and may improve nocturnal gas exchange more than oxygen alone but that the effects on disease exacerbations and progression remain unclear. ${ }^{43}$

\section{Decompensated Obesity-Hypoventilation Syndrome}

Patients with acute-on-chronic respiratory failure caused by sleep apnea syndrome, usually in combination with obesity-hypoventilation syndrome and right-sided heart failure, were treated successfully with NIV and transitioned to CPAP once stabilized. ${ }^{44}$ Sturani et $\mathrm{al}^{45}$ described the successful use of nasal NIV administered with a bilevel positive airway pressure device $\left(18 \mathrm{~cm} \mathrm{H}_{2} \mathrm{O}\right.$ inspiratory and $6 \mathrm{~cm} \mathrm{H}_{2} \mathrm{O}$ expiratory pressures) in 5 subjects who were morbidly obese (mean body mass index of $50 \mathrm{~kg} / \mathrm{m}^{2}$ ) and with severe sleep apnea. In one Spanish cohort, 54 subjects with obesity-hypoventilation syndrome (34 after exacerbations) were treated with NIV. ${ }^{46}$ None required intubation, and improvement in gas exchange after an average follow-up of 50 months was impressive $(24 \mathrm{~mm} \mathrm{Hg}$ mean increase in $\mathrm{P}_{\mathrm{aO}_{2}}$ and $17 \mathrm{~mm} \mathrm{Hg}$ mean decrease in $\left.\mathrm{P}_{\mathrm{aCO}_{2}}\right){ }^{46}$ Five subjects who lost weight were weaned off NIV, and another 16 were successfully transitioned to CPAP alone. ${ }^{46}$

In a much larger more-recent prospective Spanish cohort, all of whom were treated with NIV, the subjects with decompensated obesity-hypoventilation syndrome (173) when compared with those with exacerbations of COPD (543) had similar severities of hypercapnia and acidosis $\left(\mathrm{P}_{\mathrm{aCO}_{2}} 86 \mathrm{~mm} \mathrm{Hg}\right.$, and $\mathrm{pH} 7.22$ in both groups) but had 
Table 3. Comparison of High-Flow Nasal Therapy (HFNC), Conventional Oxygen Therapy, and NIV

\begin{tabular}{lccc}
\hline \hline & HFNC & $\begin{array}{c}\text { Conventional } \\
\text { Oxygen Therapy }\end{array}$ & NIV \\
\hline Tolerability & +++ & ++ & + \\
Comfort & +++ & ++ & + \\
Mucociliary function* & +++ & + & + \\
Eating & +++ & ++ & + \\
Speaking & +++ & ++ & + \\
Oxygenation & ++ & + & ++ \\
Ventilatory index $\dagger$ & ++ & + & + \\
Ventilatory efficiency & +++ & & + \\
Work of breathing & ++ & & \\
& & & \\
$*$ Preserves ventilatory function. & & & \\
$\dagger$ Breathing frequency $\times \mathrm{P}_{\text {aco }}$. & & & \\
HFNC = high-flow nasal cannula & & & \\
NIV = noninvasive ventilation & & & \\
$+++=$ most & & & \\
$++=$ intermediate & & & \\
$+=$ least & & & \\
\hline
\end{tabular}

lower rates of late NIV failure (9\% versus $16 \%$ ) and inhospital $(10.6 \%$ versus $18 \%)$ and 1 -y mortalities. ${ }^{47}$ The investigators concluded that NIV can effectively treat acute hypercapnic respiratory failure in patients with obesityhypoventilation syndrome, possibly with better outcomes than in patients with COPD exacerbations ${ }^{47}$ However, the quality of the studies is limited, and there are no guidelines that endorse the use of NIV for this application.

\section{HFNC in Acute Hypercapnic Respiratory Failure}

\section{Rationale for HFNC to Treat Acute Hypercapnic Respiratory Failure}

HFNC therapy has increasingly been used as a treatment for various kinds of respiratory failure over the past several years. This increasing uptake has been driven by several advantages that HFNC has over conventional higher-intensity oxygen systems (such as non-rebreather or air-entrainment masks) ${ }^{48}$ and NIV, ${ }^{49}$ including better comfort and tolerability (Table 3 ). These advantages are related to the unobtrusive nasal interfaces used with HFNC that permit unimpeded eating by mouth and speaking as well as greater heating and humidification (to body conditions), which enable patients to tolerate the high nasal flows (up to $60 \mathrm{~L} / \mathrm{min}$, depending on manufacturer) and enhances hydration of secretions. This helps to preserve mucociliary function and facilitates secretion removal in patients with bronchiectasis, ${ }^{50}$ and could be of value in patients with COPD.

Another aspect of HFNC that is relevant to patients with COPD is its ability to flush out exhaled gas from the nasopharynx, which thus reduces dead space ventilation and improves the efficiency of ventilation. In addition, HFNC reduces breathing frequency by posing an expiratory impedance that slows exhalation. These effects reduce the work of breathing per minute. Furthermore, the expiratory impedance produces PEEP that approximates $1 \mathrm{~cm} \mathrm{H}_{2} \mathrm{O}$ for every $10 \mathrm{~L} / \mathrm{min}$ flow with the mouth closed. ${ }^{51}$ Although this could contribute to a reduction in the work of breathing by counterbalancing effects of auto-PEEP, the importance of this effect in clinical settings has not been established.

HFNC also oxygenates effectively because of 2 related mechanisms. First, the high flow delivered is closer to or exceeds inspiratory flows found in patients who are dyspneic. Inspiratory flows are quite variable, depending on factors such as age, respiratory muscle function, and inspiratory resistance. But, they almost always exceed the $15 \mathrm{~L} / \mathrm{min}$ often used with non-rebreather masks and may occasionally exceed the $60 \mathrm{~L} / \mathrm{min}$ maximum flow of some of the commercially available HFNC therapy systems. ${ }^{52,53}$ This means that HFNC reduces room-air entrainment that occurs with conventional oxygen systems, which limits dilution of delivered gas and provides a higher and morereliable $\mathrm{F}_{\mathrm{IO}_{2}}$. The second mechanism has to do with flushing out dead-space gas in the nasopharynx during exhalation, which means that the initial bolus of inspired gas contains oxygen-enriched gas from the HFNC device rather than exhaled oxygen-depleted gas, again helping to deliver a more reliable $\mathrm{F}_{\mathrm{IO}_{2}}$. Results of clinical studies show enhanced oxygenation compared with conventional oxygen systems in subjects in critical care ${ }^{54}$ but not as good as NIV, presumably because of the greater positive airway pressure achieved with NIV. ${ }^{55}$

\section{Physiologic Studies That Used HFNC in Subjects With COPD}

Several small physiologic studies examined responses to short-term application of HFNC in subjects with severe stable COPD. Fraser et al $^{56}$ randomly crossed over 30 male subjects with COPD to 20 min of HFNC therapy at $30 \mathrm{~L} / \mathrm{min}$ or $20 \mathrm{~min}$ of conventional nasal cannula oxygen therapy $(2-4 \mathrm{~L} / \mathrm{min})$. They found a lower breathing frequency (15.4 versus 19.2 breaths/min), transcutaneous $\mathrm{P}_{\mathrm{CO}_{2}}$ (43.3 versus $46.7 \mathrm{~mm} \mathrm{Hg}$ ), larger tidal volume, and greater end-expiratory lung volume in the HFNC group compared with the conventional oxygen group. Atwood et $\mathrm{al}^{57} \mathrm{ex}-$ amined the effect of the Flowrest high velocity device (Vapotherm, Exeter, New Hampshire), which uses smaller-bore nasal prongs than are used with the Optiflow device (Fisher \& Paykel, Auckland, New Zealand), which has been used in most of the other studies. The high velocity device, even at lower flows (up to $35 \mathrm{~L} / \mathrm{min}$ ) is thought to augment turbulent energy and accelerate the 
Table 4. Comparison of Technical Factors Between HFNC and NIV

\begin{tabular}{lll}
\hline \hline Technical Factor & \multicolumn{1}{c}{ NIV } & \multicolumn{1}{c}{ HFNC } \\
\hline Heat & Variable & $31-37^{\circ} \mathrm{C}$ \\
Humidity & Variable & Saturated \\
Pressure & Preset inspiratory and expiratory & Variable \\
Flow & Variable & Preset continuous \\
Ventilator circuit & Single or double & Single heated \\
Oxygenation & Bleed-in or blender & Blender $\left(\mathrm{F}_{\mathrm{IO}_{2}}\right.$ \\
& & $0.21-1.0)$ \\
& \\
HFNC = high-flow nasal cannula & \\
NIV = noninvasive ventilation & \\
\hline
\end{tabular}

vortices formed in the nasal cavity and possibly enhances the flushing effect. ${ }^{58}$

The study by Atwood et al ${ }^{57}$ enrolled subjects with COPD who were on 1-2 L/min nasal oxygen at home. They were randomized to $30 \mathrm{~min}$ each of spontaneous breathing on room air, their usual low-flow conventional oxygen therapy, and HFNC with no $\mathrm{O}_{2}$ supplementation. ${ }^{57}$ The investigators hypothesized that oxygenation would be improved by HFNC compared with spontaneous breathing of room air because of the flushing of dead space but that was not the case. Only the conventional oxygen therapy setting led to an increase in oxygenation. Breathing frequency was reduced on HFNC but not in the other conditions, and $\mathrm{P}_{\mathrm{aCO}_{2}}$ was unchanged in all settings. ${ }^{57}$ The investigators calculated a ventilatory index as the product of breathing frequency and $\mathrm{P}_{\mathrm{aCO}}$ that was lower on HFNC, consistent with improved ventilatory efficiency. ${ }^{57}$

Pisani et al ${ }^{59}$ studied 14 subjects with severe COPD and hypercapnic respiratory failure when using HFNC up to $30 \mathrm{~L} / \mathrm{min}$ compared with NIV with an expiratory pressure of $4 \mathrm{~cm} \mathrm{H}_{2} \mathrm{O}$ and inspiratory pressure adjusted to tolerance. They measured the pressure-time product of the diaphragm as an index of the work of breathing by using esophageal and gastric manometry to measure transdiaphragmatic pressure. At HFNC of $30 \mathrm{~L} / \mathrm{min}$, the pressure-time product of the diaphragm per min was lower than at baseline but higher than during NIV.

These studies support the idea that HFNC could be helpful to treat an exacerbation of COPD by virtue of the ability of HFNC to reduce breathing frequency and the work of breathing. HFNC provides oxygenated gas with a precise $\mathrm{F}_{\mathrm{IO}_{2}}$ so that excessive oxygen delivery can be avoided. It also maintains hydration of secretions and mucociliary function, which thus enhances mobilization of secretions.

\section{Comparison Between HFNC and NIV}

As listed in Table 4, HFNC delivers oxygenated gas at body temperature and saturation, whereas these are vari-

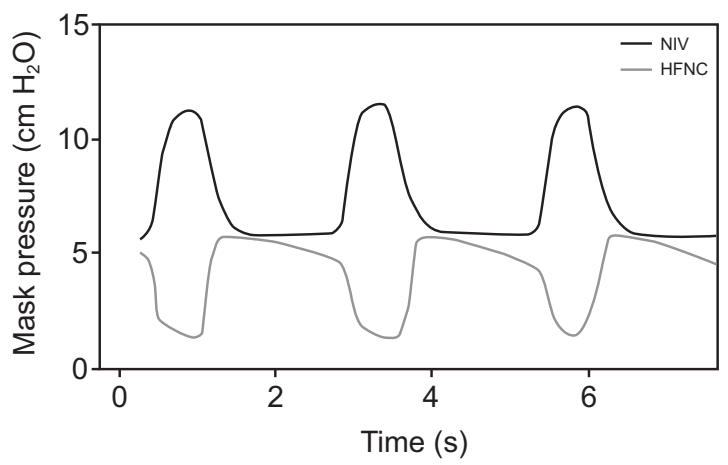

Fig. 1. Mask pressure tracing during noninvasive ventilation (NIV) by using a bi-level ventilator with inspiratory pressure of $12 \mathrm{~cm} \mathrm{H}_{2} \mathrm{O}$ and expiratory pressure of $6 \mathrm{~cm} \mathrm{H}_{2} \mathrm{O}$, and oropharyngeal pressure tracing during high-flow nasal cannula (HFNC) with flow set at $60 \mathrm{~L} / \mathrm{min}$. Expiratory pressures are similar, at roughly $6 \mathrm{~cm} \mathrm{H} \mathrm{H}_{2} \mathrm{O}$ (declining during expiration as patient expiratory flow diminishes), but during inspiration, pressure rises to the set $12 \mathrm{~cm} \mathrm{H}_{2} \mathrm{O}$ during NIV and drops to $2 \mathrm{~cm} \mathrm{H}_{2} \mathrm{O}$ during HFNC. Data are from ventilator tracings and Reference 60. Illustration was by W. Hill.

able with NIV because some practitioners do not routinely use humidification and even when humidifiers are used, heating and humidification are often partial. A major difference between the HFNC and NIV is that, with the latter, the ventilatory modes most often used are pressure targeted, with preset expiratory and inspiratory pressures, and a backup rate. Flow varies to maintain pressure. With HFNC, flow is targeted and pressure varies as determined by flow, respiratory cycle, and nasal resistance. Both HFNC and NIV supply oxygen via oxygen blenders that allow $\mathrm{F}_{\mathrm{IO}_{2}}$ to be set between 0.21 and 1.0.

As shown in Figure 1, another major difference is how nasopharyngeal (and, presumably, lower airway) pressure varies during the respiratory cycle. The expiratory pressure with HFNC reaches a peak early during expiration when the patient's expiratory flow peaks. This is in the range of $5-6 \mathrm{~cm} \mathrm{H}_{2} \mathrm{O}$ at flows of $50-60 \mathrm{~L} / \mathrm{min}$. ${ }^{60}$ The expiratory pressure then gradually diminishes as exhalation proceeds, and patient expiratory flow drops off until it dips abruptly during the onset of inspiration. As long as the HFNC flow exceeds the patient's inspiratory flow, nasophayngeal pressure will remain positive but may drop to 1 or $2 \mathrm{~cm} \mathrm{H}_{2} \mathrm{O}$. With NIV, nasopharyngeal, and airway pressures depend on the preset pressures as long as the air leak is not excessive. In Figure 1, inspiratory and expiratory pressures during NIV are set at 12 and $6 \mathrm{~cm} \mathrm{H}_{2} \mathrm{O}$, respectively. During expiration, HFNC therapy and NIV pressures are almost superimposable, but, during inspiration, NIV pressure rises to $12 \mathrm{~cm} \mathrm{H}_{2} \mathrm{O}$ and HFNC pressure drops to $2 \mathrm{~cm} \mathrm{H}_{2} \mathrm{O}$. This will likely have major differential effects on the work of breathing, with NIV more effectively assisting ventilation and improving oxygenation in situations in which the higher inspiratory pressure is likely 
to be helpful, such as severe COPD exacerbations or with acute cardiogenic pulmonary edema.

\section{Evidence for Efficacy of HFNC in Acute Hypercapnic Respiratory Failure}

HFNC is not a new therapy, but it has emerged as an increasingly used treatment for respiratory failure over the past 5 years. The evidence base to support its use is accumulating but is not yet firmly established. The strongest evidence is for use in hypoxemic respiratory failure caused by ARDS or pneumonia, ${ }^{61}$ or in subjects who are hypoxic and are postoperative ${ }^{55}$ or postextubation. ${ }^{62-64}$ Although some meta-analyses concluded that HFNC is superior to conventional oxygen therapy with regard to avoidance of intubation or escalation of therapy, ${ }^{65}$ others ${ }^{66,67}$ have not demonstrated such benefits in comparison with NIV. More studies with consistent methodologies and better characterized patient populations will be needed before optimal indications and applications can be adequately addressed.

Few studies reported on the performance of HFNC in acute hypercapnic respiratory failure and those available thus far have focused only on COPD. In one retrospective study, 33 subjects with acute hypercapnia (mean $\mathrm{P}_{\mathrm{aCO}_{2}}$ of $55 \mathrm{~mm} \mathrm{Hg}$ ), a third with COPD, were treated with HFNC (average $\mathrm{F}_{\mathrm{IO}_{2}}$ of 0.45 and flow of $41 \mathrm{~L} / \mathrm{min}$ ). After initial conventional oxygen therapy during which $\mathrm{P}_{\mathrm{aCO}}$ rose by a mean of $1 \mathrm{~mm} \mathrm{Hg}$, patients were switched to HFNC and $\mathrm{P}_{\mathrm{aCO}_{2}}$ fell by $4 \mathrm{~mm} \mathrm{Hg}$ at both 1 and $24 \mathrm{hrs}$ after HFNC initiation. 68

A controlled study based in the emergency departments at 5 centers randomized 204 subjects with respiratory compromise to receive high-velocity nasal insufflation (HVNI Vapotherm, average flow $30 \mathrm{~L} / \mathrm{min}$ ) versus NIV (average inspiratory positive airway pressure, $13 \mathrm{~cm} \mathrm{H}_{2} \mathrm{O}$, and expiratory positive airway pressure, $\left.6 \mathrm{~cm} \mathrm{H}_{2} \mathrm{O}\right) .{ }^{7} \mathrm{COPD}$ was the most-common presenting condition, which accounted for some $40 \%$ of the subjects, with general dyspnea and congestive heart failure the next most common condition. Seven percent of subjects in the high-velocity group required intubation compared with $13 \%$ in the NIV group, a nonsignificant difference. However, failure of the initial device due to persisting respiratory distress or inability to adequately ventilate or oxygenate led to crossover to the other device in 19\% (overall failure rate, 26\%) in the high-velocity group compared with $6 \%$ (overall failure, $19 \%$ ) in the NIV group. The investigators concluded that high-velocity insufflation is noninferior to NIV for treating acute respiratory failure in the emergency department, although it is possible that many of the subjects who crossed over to NIV from the high-velocity group avoided intubation because of NIV. ${ }^{7}$ Thus, if they had not crossed over, then the intubation rate in the high-velocity group could have been higher and the conclusion could have been dif-
Table 5. Possible Indications for High-Flow Nasal Therapy in Patients With COPD and Acute Hypercapnic Respiratory Failure

\begin{tabular}{l}
\hline Possible Indication \\
\hline Moderate severity exacerbations \\
Intolerant of NIV but no need for immediate intubation \\
COPD exacerbation with difficulty mobilizing secretions \\
Use during breaks from NIV \\
Evidence base for use of high-flow nasal therapy for acute hypercapnic respiratory failure in \\
COPD is much weaker than for NIV, which should be considered the ventilatory modality of \\
first choice. \\
NIV = noninvasive ventilation \\
\hline
\end{tabular}

ferent. In a subgroup analysis of 65 subjects with hypercapnic respiratory failure obtained from this study, the intubation rate tended to be lower $(6 \%)$ in the high-velocity group than in the NIV group (16\%), but, because of the difference in crossovers, the overall failure rates were similar, at $23.5 \%$ and $25.8 \%$, respectively. ${ }^{7}$

Although these findings support the idea that many patients with hypercapnic respiratory failure due to COPD could be treated successfully with HFNC therapy, this inference must be made with caveats. First, examination of the COPD cohort was based on a post hoc analysis and prospective RCTs that focus specifically on subjects with hypercapnic respiratory failure are lacking. Second, blinding is not possible with these studies and bias cannot be eliminated. Third, based on the pressure contour differences between HFNC and NIV discussed above, it is possible, perhaps even likely, that patients with more-severe exacerbations who require higher levels of pressure support to assist ventilation will have higher success rates with NIV. Until more data are available, NIV should continue to be viewed as the first-choice modality to treat acute hypercapnic respiratory failure due to COPD. HFNC may have advantages in milder exacerbations, especially in the presence of increased secretions or in patients who are intolerant of NIV (Table 5). Another possible application of HFNC is use as a complementary therapy instead of standard oxygen with NIV during breaks. In a recent RCT by Spoletini et al, ${ }^{69}$ HFNC therapy had no effect on the duration of NIV sessions or breaks, but it was more comfortable and facilitated eating better than conventional oxygen and prevented the increased tachypnea and dyspnea that occurred with conventional oxygen during breaks.

\section{Conclusions}

NIV is well established as the preferred form of ventilatory assistance for patients with acute hypercapnic respiratory failure and in patients with COPD, improving dyspnea and gas exchange, and avoiding the need for in- 


\section{Noninvasive Support for Acute Hypercapnic Respiratory FaILURe}

tubation as well as reducing morbidity and mortality rates. It also has likely beneficial effects in other forms of acute hypercapnic respiratory failure, including those caused by asthma, cystic fibrosis, and obesity hypoventilation. A newer form of noninvasive ventilatory support, HFNC therapy, has emerged in recent years and is capable of improving ventilatory efficiency and reducing the work of breathing in patients with severe COPD. Results of early studies indicate that some patients with acute hypercapnic respiratory failure can be managed with HFNC in addition to or even instead of NIV, but more study is necessary before specific recommendations can be made.

\section{REFERENCES}

1. Chandra D, Stamm JA, Taylor B, Ramos RM, Satterwhite L, Krishnan JA, et al. Outcomes of non-invasive ventilation for acute exacerbations of COPD in the United States, 1998-2008. Am J Respir Crit Care Med 2012;185(2):152-159.

2. Nava S, Hill N. Non-invasive ventilation in acute respiratory failure. Lancet 2009;374(9685):250-259.

3. Rochwerg B, Brochard L, Elliott MW, Hess D, Hill NS, Nava S, et al.; Raoof S Members Of The Task Force. Official ERS/ATS clinical practice guidelines: noninvasive ventilation for acute respiratory failure. Eur Respir J 2017;50(2). pii:1602426.

4. Miro AM, Shivaram U, Hertig I. Continuous positive airway pressure in COPD patients in acute hypercapnic respiratory failure. Chest 1993;103(1):266-288.

5. de Lucas P, Tarancon C, Puente L, et al. Nasal continuous positive airway pressure in patients with COPD in acute respiratory failure. A study of the immediate effects. Chest 1993;104(6):1694-1697.

6. Corrado A, Gorini M, Melej R, Baglioni S, Mollica C, Villella G, et al. Iron lung versus mask ventilation in acute exacerbation of COPD: a randomised crossover study. Intensive Care Med 2009;35(4):648655.

7. Doshi P, Whittle JS, Bublewicz M, Kearney J, Ashe T, Graham R, et al. High-velocity nasal insufflation in the treatment of respiratory failure: a randomized clinical trial. Ann Emerg Med 2018;72(1):7383.e5.

8. Nourdine K, Combes P, Carton MJ, Beuret P, Cannamela A, Ducreux JC. Does noninvasive ventilation reduce the ICU nosocomial infection risk? A prospective clinical survey. Intensive Care Med 1999;25(6):567-573.

9. Girou E, Brun-Buisson C, Taillé S, Lemaire F, Brochard L. Secular trends in nosocomial infections and mortality associated with noninvasive ventilation in patients with exacerbation of COPD and pulmonary edema. JAMA 2003;290(22):2985-2991.

10. Confalonieri M, Potena A, Carbone G, Porta RD, Tolley EA, Umberto Meduri G. Acute respiratory failure in patients with severe community-acquired pneumonia. A prospective, randomized evaluation of noninvasive ventilation. Am J Respir Crit Care Med 1999; 160(5 Pt1):1585-1591.

11. Nava S, Evangelisti I, Rampulla C, Compagnoni ML, Fracchia C, Rubini F. Human and financial costs of noninvasive mechanical ventilation in patients affected by COPD and acute respiratory failure. Chest 1997;111(6):1631-1638.

12. Carlucci A, Richard JC, Wysocki M, Lepage E, Brochard L. SRLF Collaborative Group on Mechanical Ventilation. Noninvasive versus conventional mechanical ventilation. An epidemiologic survey Am J Respir Crit Care Med 2001;163(4):874-880.
13. Demoule A, Girou E, Richard JC, Taillé S, Brochard L. Increased use of noninvasive ventilation in French intensive care units. Intensive Care Med 2006;32(11):1747-1755.

14. Esteban A, Ferguson ND, Meade MO, Arabi Y, Apezteguía C, González M, et al.; VENTILA Group. Evolution of mechanical ventilation in response to clinical research. Am J Respir Crit Care Med 2008;177(2):170-177.

15. Esteban A, Frutos-Vivar F, Muriel A, Ferguson ND, Peñuelas O, Abraira $\mathrm{V}$, et al. Evolution of mortality over time in patients receiving mechanical ventilation. Am J Respir Crit Care Med 2013;188(2): 220-230.

16. Maheshwari V, Paioli D, Rothaar R, Hill NS. Utilization of noninvasive ventilation in acute care hospitals: a regional survey. Chest 2006;129(5):1226-1233.

17. Ozsancak Ugurlu A, Sidhom SS, Khodabandeh A, Ieong M, Mohr C, Lin DY, et al. Use and outcomes of noninvasive positive pressure ventilation in acute care hospitals in Massachusetts. Chest 2014; 145(5):964-971.

18. Stefan MS, Shieh MS, Pekow PS, Hill N, Rothberg MB, Lindenauer $\mathrm{PK}$. Trends in mechanical ventilation among patients hospitalized with acute exacerbation of COPD in the United States, 2001 to 2011. Chest 2015;147(4):959-968.

19. Kaul S, Pearson M, Coutts I, Lowe D, Roberts M. Non-invasive ventilation (NIV) in the clinical management of acute COPD in 233 UK hospitals: results from the RCP/BTS 2003 National COPD Audit. COPD 2009;6(3):171-176.

20. Hong SB, Oh BJ, Kim YS, Kang EH, Kim CH, et al.; Koren study group on respiratory failure (KOSREF). Characteristics of mechanical ventilation employed in intensive care units: a multicenter survey of hospitals. J Korean Med Sci 2008;23(6):948-953.

21. Brochard L, Mancebo J, Wysocki M, Lofaso F, Conti G, Rauss A, et al. Noninvasive ventilation for acute exacerbations of chronic obstructive pulmonary disease. N Engl J Med 1995;333(13):817-822.

22. Appendini L, Patessio A, Zanaboni S, Carone M, Gukov B, Donner CF, Rossi A. Physiologic effects of positive end-expiratory pressure and mask pressure support during exacerbations of chronic obstructive pulmonary disease. Am J Respir Crit Care Med 1994;149(5): 1069-1076.

23. Kramer N, Meyer TJ, Meharg J, Cece RD, Hill NS. Randomized, prospective trial of noninvasive positive pressure ventilation in acute respiratory failure. Am J Respir Crit Care Med 1995;151(6):17991806.

24. Mehta S, Hill NS. Noninvasive ventilation. State of the art. Am J Respir Crit Care Med 2001;163(2):540-577.

25. Lightowler JV, Wedzicha JA, Elliott MW, Ram FS. Noninvasive positive pressure ventilation for the treatment of respiratory failure due to exacerbations of chronic obstructive pulmonary disease (Cochrane review). BMJ 2003;326(7382):185-189.

26. Quon BS, Gan WQ, Sin DD. Contemporary management of acute exacerbations of COPD: a systematic review and metaanalysis. Chest 2008;133(3):756-766.

27. Lindenauer PK, Stefan MS, Shieh MS, Pekow PS, Rothberg MB, Hill NS. Outcomes associated with invasive and noninvasive ventilation among patients hospitalized with exacerbations of chronic obstructive pulmonary disease. JAMA Intern Med 2014;174(12): 1982-1993.

28. Nava S, Ambrosino N, Clini E, Prato M, Orlando G, Vitacca M, et al. Noninvasive mechanical ventilation in the weaning of patients with respiratory failure due to chronic obstructive pulmonary disease: a randomized, controlled trial. Ann Intern Med 1998;128(9): 721-728.

29. Ferrer M, Esquinas A, Arancibia F, Bauer TT, Gonzalez G, Carrillo A, et al. Noninvasive ventilation during persistent weaning failure: a 


\section{Noninvasive Support for Acute Hypercapnic Respiratory FaILURe}

randomized, controlled trial. Am J Respir Crit Care Med 2003;168(1): 70-76.

30. Ferrer M, Sellarés J, Valencia, M Carrillo A, Gonzalez G, Badia JR, et al. Non-invasive ventilation after extubation in hypercapnic patients with chronic respiratory disorders: randomised controlled trial. Lancet 2009;374(9695):1082-1088.

31. Auriant I, Jallot A, Hervé P, Cerrina J, Le Roy Ladurie F, et al. Noninvasive ventilation reduces mortality in acute respiratory failure following lung resection. Am J Respir Crit Care Med 2001;164(7): 1231-1235

32. Levy M, Tanios MA, Nelson D, Short K, Senechia A, Vespia J, Hill NS. Outcomes of patients with do-not-intubate orders treated with noninvasive ventilation. Crit Care Med 2004;32(10):2002-2007.

33. Schettino G, Altobelli N, Kacmarek RM. Noninvasive positive pressure ventilation reverses acute respiratory failure in select "do-notintubate" patients. Crit Care Med 2005;33(9):1976-1982.

34. Meduri GU, Cook TR, Turner RE, Cohen M, Leeper KV. Noninvasive positive pressure ventilation in status asthmaticus. Chest 1996; 110(3):767-774

35. Fernández MM, Villagrá A, Blanch L, Fernández R. Non-invasive mechanical ventilation in status asthmaticus. Intensive Care Med 2001;27(3):486-492.

36. Soroksky A, Stav D, Shpirer I. A pilot prospective, randomized, placebo-controlled trial of bilevel positive airway pressure in acute asthmatic attack. Chest 2003;123(4):1018-1025.

37. Soma T, Hino M, Kida K, Kudoh S. A prospective and randomized study for improvement of acute asthma by non-invasive positive pressure ventilation (NPPV). Intern Med 2008;47(6):493-501.

38. Gupta D, Nath A, Agarwal R, Behera D. A prospective randomized controlled trial on the efficacy of noninvasive ventilation in severe acute asthma. Respir Care 2010;55(5):536-543.

39. Lavoie TL, Krishnan R, Siegel HR, Maston ED, Fredberg JJ, Solway J, Dowell ML. Dilatation of the constricted human airway by tidal expansion of lung parenchyma. Am J Respir Crit Care Med 2012; 186(3):225-232

40. Lim WJ, Mohammed Akram R, Carson KV, Mysore S, Labiszewski NA, Wedzicha JA, et al. Non-invasive positive pressure ventilation for treatment of respiratory failure due to severe acute exacerbations of asthma. Cochrane Database Syst Rev 2012;12:CD004360.

41. Madden BP, Kariyawasam H, Siddiqi AJ, Machin A, Pryor JA, Hodson ME. Noninvasive ventilation in cystic fibrosis patients with acute or chronic respiratory failure. Eur Respir J 2002;19(2):310313.

42. Hill AT, Edenborough FP, Cayton RM, Stableforth DE. Long-term nasal intermittent positive pressure ventilation in patients with cystic fibrosis and hypercapnic respiratory failure (1991-1996). Respir Med 1998;92(3):523-526.

43. Moran F, Bradley JM, Piper AJ. Non-invasive ventilation for cystic fibrosis. Cochrane Database Syst Rev 2017;2:CD002769.

44. Piper AJ, Sullivan CE. Effects of short-term NIPPV in the treatment of patients with severe obstructive sleep apnea and hypercapnia. Chest 1994;105(2):434-440.

45. Sturani C, Galavotti V, Scarduelli C, Sella D, Rosa A, Cauzzi R, Buzzi G. Acute respiratory failure, due to severe obstructive sleep apnoea syndrome, managed with nasal positive pressure ventilation. Monaldi Arch Chest Dis 1994;49(6):558-560.

46. Pérez de Llano LA, Golpe R, Ortiz Piquer M, Veres Racamonde A, Vázquez Caruncho M, Caballero Muinelos O, Alvarez Carro C. Short-term and long-term effects of nasal intermittent positive pressure ventilation in patients with obesity-hypoventilation syndrome. Chest 2005;128(2):587-594.

47. Carrillo A, Ferrer M, Gonzalez-Diaz G, Lopez-Martinez A, Llamas $\mathrm{N}$, Alcazar M, et al. Noninvasive ventilation in acute hypercapnic respiratory failure caused by obesity hypoventilation syndrome and chronic obstructive pulmonary disease. Am J Respir Crit Care Med 2012;186(12):1279-1285

48. Roca O, Riera J, Torres F, Masclans JR. High-flow oxygen therapy in acute respiratory failure. Respir Care 2010;55(4):408-413.

49. Spoletini G, Alotaibi M, Blasi F, Hill NS. Heated humidified highflow nasal oxygen in adults: mechanisms of action and clinical implications. Chest 2015;148(1):253-261.

50. Hasani A, Chapman TH, McCool D, Smith RE, Dilworth JP, Agnew JE. Domiciliary humidification improves lung mucociliary clearance in patients with bronchiectasis. Chron Respir Dis 2008;5(2):81-86.

51. Parke R, McGuinness S, Eccleston M. Nasal high-flow therapy delivers low level positive airway pressure. Br J Anaesth 2009;103(6): 886-890.

52. Chen IC, Kuo J, Ko WJ, Shih HC, Kuo CD. Increased flow resistance and decreased flow rate in patients with acute respiratory distress syndrome: the role of autonomic nervous modulation. J Chin Med Assoc 2016;79(1):17-24.

53. Janssens W, VandenBrande P, Hardeman E, De Langhe E, Philps T, Troosters T, Decramer M. Inspiratory flow rates at different levels of resistance in elderly COPD patients. Eur Respir J 2008;31(1):78-83.

54. Sztrymf B, Messika J, Bertrand F, Hurel D, Leon R, Dreyfuss D, Ricard JD. Beneficial effects of humidified high flow nasal oxygen in critical care patients: a prospective pilot study. Intensive Care Med 2011;37(11):1780-1786.

55. Stéphan F, Barrucand B, Petit P, Rézaiguia-Delclaux S, Médard A, Delannoy B, et al.; BiPOP Study Group. High-flow nasal oxygen vs noninvasive positive airway pressure in hypoxemic patients after cardiothoracic surgery: a randomized clinical trial. JAMA 2015; 313(23):2331-2339.

56. Fraser JF, Spooner AJ, Dunster KR, Anstey CM, Corley A. Nasal high flow oxygen therapy in patients with COPD reduces respiratory rate and tissue carbon dioxide while increasing tidal and end-expiratory lung volumes: a randomised crossover trial. Thorax 2016;71(8):759-761.

57. Atwood CW Jr, Camhi S, Little KC, Paul C, Schweikert H, Macmillan NJ, Miller TL. Impact of heated humidified high flow air via nasal cannula on respiratory effort in patients with chronic obstructive pulmonary disease. Chronic Obstr Pulm Dis 2017;4(4):279-286.

58. Miller T, Saberi B, Saberi S. Computational fluid dynamics modeling of extrathoracic airway flush: evaluation of high flow nasal cannula design elements. J Pulm Respir Med 2016;6(5):376.

59. Pisani L, Fasano L, Corcione N, Comellini V, Musti MA, Brandao $\mathrm{M}$, et al. Change in pulmonary mechanics and the effect on breathing pattern of high flow oxygen therapy in stable hypercapnic COPD. Thorax 2017;72(4):373-375.

60. Corley A, Caruana LR, Barnett AG, Tronstad O, Fraser JF. Oxygen delivery through high-flow nasal cannulae increase end-expiratory lung volume and reduce respiratory rate in post-cardiac surgical patients. Br J Anaesth 2011;107(6):998-1004.

61. Frat JP, Thille AW, Mercat A, Girault C, Ragot S, Perbet S, et al.; FLORALI Study Group, REVA Network. High-flow oxygen through nasal cannula in acute hypoxemic respiratory failure. $\mathrm{N}$ Engl J Med 2015;372(23):2185-2196

62. Maggiore SM, Idone FA, Vaschetto R, Festa R, Cataldo A, Antonicelli $\mathrm{F}$, et al. Nasal high-flow versus Venturi mask oxygen therapy after extubation. Effects on oxygenation, comfort, and clinical outcome. Am J Respir Crit Care Med 2014;190(3):282-288.

63. Hernández G, Vaquero C, González P, Subira C, Frutos-Vivar F, Rialp G, et al. Effect of postextubation high-flow nasal cannula vs conventional oxygen therapy on reintubation in low-risk patients: a randomized clinical trial. JAMA 2016;315(13):1354-1361.

64. Hernández G, Vaquero C, Colinas L, Cuena R, González P, Canabal A, et al. Effect of postextubation high-flow nasal cannula vs noninvasive ventilation on reintubation and postextubation respiratory 
failure in high-risk patients: a randomized clinical trial. JAMA 2016; 316(15):1565-1574.

65. Nedel WL, Deutschendorf C, Moraes Rodrigues Filho E. High-flow nasal cannula in critically ill subjects with or at risk for respiratory failure: a systematic review and meta-analysis. Respir Care 2017; 62(1):123-132.

66. Maitra S, Som A, Bhattacharjee S, Arora MK, Baidya DK. Comparison of high-flow nasal oxygen therapy with conventional oxygen therapy and noninvasive ventilation in adult patients with acute hypoxemic respiratory failure: A meta-analysis and systematic review. J Crit Care 2016;35:138-144.
67. Zhao H, Wang H, Sun F, Lyu S, An Y. High-flow nasal cannula oxygen therapy is superior to conventional oxygen therapy but not to noninvasive mechanical ventilation on intubation rate: a systematic review and meta-analysis. Crit Care 2017;21(1):184.

68. Kim ES, Lee H, Kim SJ, Park J, Lee YJ, Park JS, et al. Effectiveness of high-flow nasal cannula oxygen therapy for acute respiratory failure with hypercapnia. J Thorac Dis 2018;10(2):882-888.

69. Spoletini G, Mega C, Pisani L, Alotaibi M, Khoja A, Price LL, et al. High-flow nasal therapy vs standard oxygen during breaks off noninvasive ventilation for acute respiratory failure: a pilot randomized controlled trial. J Crit Care 2018;48(Can’t get issue from record):418-425.

\section{Discussion}

MacIntyre: Nick [Hill], one of the areas you didn't touch on is the use of NIV, not in the acute care setting but in chronic hypercapnia.

Hill: I was specifically asked to talk about acute so that's what I did.

MacIntyre: That's fine, you did a superb job, but at some point in this conference we need to at least address it because it's a hot topic and Medicare is quite concerned about it. The use of nocturnal NIV for patients with COPD who are hypercarbic is increasing. Indeed, the whole idea of the German approach, ${ }^{1}$ when you try to reduce $\mathrm{P}_{\mathrm{aCO}}$ appears to offer benefit but is it really worth the trouble? These are important issues in NIV, and, because we don't have a formal talk on it, could you summarize what you think the role is in the patient with chronic hypercapnic COPD?

Hill: I appreciate your question, part of the reason I didn't address it is the same reason you didn't touch on HFNC in your talk; there's not time. There have been some very influential favorable studies over the past several years, starting with Köhnlein et $\mathrm{al}^{2}$ in 2014 , in which there was a very impressive mortality improvement, $30 \%$ in the controls down to $\sim 12 \%$ in subjects treated with NIV. More recently, we had the HOT-HMV (home oxygen therapy-home mechanical ventilation) trial $^{3}$ out of England, and there they looked at a combined end point of death and hospitalization, and found that the first hospitalization event occurred at an average of 1.3 months in controls and 4 months in the subjects on NIV, a very dramatic difference that favored NIV. We then had another study out of Holland by Struik et $\mathrm{al}^{4}$ who found absolutely no benefit whatsoever. So, it's still an area of controversy. These studies used different approaches. The German study ${ }^{1}$ didn't use the high-intensity approach championed by Windisch's group 5 with high inspiratory pressures (up to $40 \mathrm{~cm} \mathrm{H}_{2} \mathrm{O}$ ) and breathing frequencies to completely control ventilation. Rather, the study by Köhnlein et $\mathrm{al}^{2}$ used average inspiratory pressures in the low 20s, as did the other recent studies. Despite the controversy, I do think there is a role for NIV in patients with severe stable COPD in the out-patient setting, but it's hard to know exactly which patient to select and what technique to use. I think most clinicians agree that in order to benefit from long-term NIV, these patients need to be chronically hypercapnic. Medicare guidelines have required a stable daytime $\mathrm{P}_{\mathrm{aCO}}$ of $\geq 52 \mathrm{~mm} \mathrm{Hg}$, a guideline that you helped them establish 20 years ago.

\section{MacIntyre: Thank you.}

Hill: Other characteristics they should have aren't so clear. Results of studies have suggested that patients who tend to retain more $\mathrm{CO}_{2}$ when put on oxygen or are frequent flyers might benefit from home NIV. Although it wasn't specifically addressed in the recent studies, I think what hap- pens to breathing during sleep may be really important in explaining the favorable responses of some patients. Many of these patients may have an overlap syndrome that consists of COPD and sleep apnea. This may render them more hypercapnic than patients with a similar degree of airway obstruction but without sleep apnea, and more likely to respond to positive airway pressure therapy. I also think we should be using higher inspiratory pressures than what used to be the case, aiming for the low $20 \mathrm{~s} \mathrm{~cm}_{2} \mathrm{O}$, as was done in the recent studies. Results of one preliminary uncontrolled study reported favorable findings in stable patients with severe COPD treated with the proprietary AVAPS-AE (average volume-assured pressure support with auto-expiratory positive airway pressure) mode, but it is important to point out that the HOTHMV study ${ }^{3}$ used standard bi-level ventilators.

Scott: I appreciate what you're saying about higher flows for HFNC. My assessment of the literature seems to be that more positive studies have higher flows. I wonder if what's happening is that practitioners are starting at a lower flow in select patients, letting the patient acclimate, but, what's happening is that we aren't making the subsequent adjustments. I hope that, as the literature evolves, we can move toward figuring out a better way to start low if we need to get somebody acclimated. In your practice, are you seeing patients or having problems getting them acclimated to those higher flows? 
Hill: No. You run into intolerance with some patients at $60 \mathrm{~L} / \mathrm{min}$ but the vast majority of people will tolerate 45 to $50 \mathrm{~L} / \mathrm{min}$ at initiation. Your point is correct that, if you start at a given flow, you're likely to stay there. We have performed a study that examined the use of HFNC compared with standard oxygen therapy during breaks from NIV. We started at too low a flow $(35 \mathrm{~L} / \mathrm{min})$ and instructed therapists to up-titrate as tolerated, but the average flow after titration was only $38 \mathrm{~L} / \mathrm{min}$. So, in retrospect, I don't think we started high enough.

\section{REFERENCES}

1. Liao H, Pei W, Li H, Luo Y, Wang K, Li $\mathrm{R}$, et al. Efficacy of long-term noninvasive positive pressure ventilation in stable hypercapnic COPD patients with respiratory failure: a meta-analysis of randomized controlled trials. Int J Chron Obstruct Pulmon Dis 2017; 12(Can't get issue from record): 2977-2985.

2. Köhnlein T, Windisch W, Köhler D, Drabik A, Geiseler J, Hartl S, et al. Non-invasive positive pressure ventilation for the treatment of severe stable chronic obstructive pulmonary disease: a prospective, multicentre, randomised, controlled clinical trial. Lancet Respir Med 2014;2(9):698-705.

3. Murphy PB, Rehal S, Arbane G, Bourke S, Calverley PMA, Crook AM, et al. Effect of home noninvasive ventilation with oxygen therapy vs oxygen therapy alone on hospital readmission or death after an acute COPD exacerbation: a randomized clinical trial. JAMA 2017;317(21):2177-2186.

4. Struik FM, Sprooten RT, Kerstjens HA, Bladder G, Zijnen M, Asin J, et al. Nocturnal non-invasive ventilation in COPD patients with prolonged hypercapnia after ventilatory support for acute respiratory failure: a randomised, controlled, parallel-group study. Thorax 2014 Sep;69(9):826-834.

5. Storre JH, Matrosovich E, Ekkernkamp E, Walker DJ, Schmoor C, Dreher M, Windisch W. Home mechanical ventilation for COPD: high-intensity versus target volume noninvasive ventilation. Respir Care 2014;59(9):1389-1397.

This article is approved for Continuing Respiratory Care Education credit. For information and to obtain your CRCE

(free to AARC members) visit

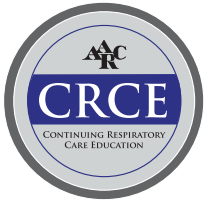

